cerebral arteriosclerosis and vertebrobasilar insufficiency are substituted and by inference the suggestion made that nothing can be done. I feel that any examination of a geriatric patient must include measurement of the blood pressure in both the lying and standing position.

You ask, "Does postural hypotension, especially over the age of 75 , matter?" There can be no doubt that this condition frequently contributes to accidents at home leading to fractured limbs, secondary hypothermia, and, perhaps most commonly, an inability to maintain independent existence in the home. Salt supplements-up to $8 \mathrm{~g}$ per day of sodium chloride (B.P.C.) in divided doses or up to $40 \mathrm{mEq}$ of Slow Sodium per day-have never upset any of my patients to date and have not yet precipitated heart failure in this age group. Cox et al. ${ }^{1}$ have suggested that there is a significant reduction in the total exchangable potassium in postural hypotension. Perhaps this is yet another manifestation of the "hypokalaemic syndrome" of old age so well known to geriatricians and seen with such depressing regularity in elderly people referred to geriatric departments because they have "fits and faints." 2 The effect of treatment with potassium and salt supplements may be very dramatic, changing a potential hospital patient or additional resident in the social services old peoples' homes to someone who can manage to live in the community.-I am, etc.,

Manor Park Hospital,

Manor
Bristol

1 Cox, J. R., Admani, A. K., Agarwal, M. L., and 2 Abel, P., Age and Ageing, 1973, 2, 112. 287

\section{The Solitary Thyroid Nodule}

SIR,-It is with some hesitation that I write to question a leading article (10 November, p. 310) which propounds a commonly accepted policy of treatment. Nonetheless, your advice for dealing with the malignant nodule deserves examination. Lobectomy and, for cosmetic reasons, removal of the isthmus, pyramidal lobe, and a very small flake from the opposite side is described as the definitive operation for a malignant nodule, though total thyroidectomy is proposed when lymph nodes are involved. Frozen-section examination of the thyroid is dismissed as being difficult and unnecessary.

The malignant nodule poses several problems, one of the most important being diagnosis, not only before but also at operation. Because of uncertainty about the diagnosis, surgeons have hesitated to subject patients to total thyroidectomy; yet it is difficult to accept that lobectomy is a logical alternative when there are many reports to show that papillary and follicular carcinoma are either multicentric in origin or undergo intraglandular spread-figures commonly accepted are 20-36\%, though Clark, using whole-gland serial sections, suggested an even higher involvement of the opposite lobe. ${ }^{2}$ Though it may aid subsequent radioactive iodine treatment, it would seem to be a little late in the day to perform total thyroidectomy only when lymph nodes are involved. Frozensection examination for the suspicious thyroid nodule was introduced here by the late Winston Evans and continues to be routinely available. In practice, this has come to be regarded as not only a useful but in many instances an essential examination.

On the basis of a firm diagnosis at the time of operation a total or "near total" thyroidectomy would seem to be more appropriate to the pathology of these tumours. Clinical recurrence in the opposite lobe after lobectomy is, of course, much less than might be expected, ${ }^{3}$ but it does not follow from this clinicopathological conundrum that lobectomy is the proper operation. The risk may be small, but in an individual patient there is no way of knowing whether a focus of carcinoma left in the opposite lobe will remain latent or develop into a clinical recurrence. There may be arguments based on the risk of hypoparathyroidism for advocating "near total" in preference to tota thyroidectomy, but the rationale for preserving most of the opposite lobe-all but a very small flake-rather than removing most of it is not apparent.-I am, etc.,

\section{P. AtKINS}

Thyroid Clinic,

David Lewis Northern Hospital,
Liverpool

$$
\begin{aligned}
& 1 \text { Winship, T., Cancer, 1967, 20, } 1815 . \\
& \text { Clark, R. L., Ibanez, M. L., and White, E. C., } \\
& \text { Archives of Surgery, 1966, 92, 23. } \\
& 3 \text { Tollefsen, H. R., and DeCosse, J. J., American } \\
& \text { fournal of Surgery, 1963, 106, 728. }
\end{aligned}
$$

St.

St. George's Hospital,

1 Russell, W. O., Ibanez, M. L., Clark, R. L., and White, E. C., Cancer, 1963, 16, 1425.

Thompson, N. W., and Harness, J. K., Surgery, Gynecology and Öbstetrics, 1970, 131, 861. Riddell, V., British fournal of Surgery, 1970, 57, 1 .

4 Rosswick, R. P., Lancet, 1973, 1, 72

\section{Anaesthetic Safety Devices}

SIR,-I suppose that it is a sign of the times that Drs. H. T. Davenport and B. M. Wright (10 November, p. 357) and others should spend time and money inventing anaesthetic safety devices. What is wrong with staying with your patient? If, as sometimes is inevitable, you have to leave him briefly, then all you need do is to depute someone with the faculties of sight and speech to watch the flowmeters and, if there is any change in their position, to shout. This method served me well for 43 years.-I am, etc.,

Chislehurst, Kent

FOLLIOTT SANDFORD

Operator-anaesthetists in Dentistry

SIR,-Your recent leading article on this subject (10 November, p. 310) was excellent until the penultimate paragraph, where I feel that the treatment advocated leaves much to be desired.

Firstly, the work of Russell et al. ${ }^{1}$ has shown that in $87.5 \%$ of thyroids in which a carcinoma (of any histological type) has developed there is a spread either across the midline or to pericapsular lymph nodes of the opposite side. Thus only a total thyroidectomy can have any real hope of eradicating the disease surgically. To advocate total thyroidectomy if nodes are positive but not otherwise is surely illogical.

Secondly, while the problems of giving an opinion on frozen section are great, I do not feel that the inability of a colleague to give a firm opinion on every occasion should mean that one never asks him to give one at all. If on frozen-section biopsy the nodule is found to be malignant then the proper operation can be carried out at once. The main risk of total thyroidectomy is bilateral recurrent nerve palsy, and this matter has been amply discussed elsewhere. ${ }^{3}$ The use of a nerve stimulator should obviate this danger and thus the proper operation can be performed. 45

Finally, I am amazed that no mention is made of radioisotopes in the treatment. To wait until palpable masses are present is surely to wait too long when small, impalpable nodes or other secondaries from differentiated carcinoma can be destroyed simply, by non-invasive means, and without risk to the patient.

This is not the place for a full discussion of the treatment of this relatively rare disease; but your leading article must prompt those interested in carcinoma of the thyroid to make a plea that the treatment advocated be the most complete that modern resources allow in order to give our patients the best prognosis. The biological behaviour of the
SIR,-I have in the past, with certain provisos, supported ${ }^{1}$ the practice of the dentist giving his own anaesthetics, having previously advanced evidence ${ }^{2}$ suggesting that this practice was not a cause of deaths. It seemed that their probable cause in nearly every case was the head-up position of the patient, and I gave reasons for thinking that bringing in a second practitioner to give the anaesthetic was unlikely to lessen the risk. The only remedy, I concluded, was to abandon the head-up position.

Studies of subsequent fatalities have substantiated this view, which was put forward in April 1966. During the ensuing 31 years there were 15 deaths in the dental chair. ${ }^{3}$ In 12 of the cases the anaesthetic was given by a second practitioner, eight of whom were specialist anaesthetists. Of the latters' patients, all but one were young and healthy and in every case the operation was brief and trivial. During the next three years (1970-2) there were a further 13 deaths in Britain, ${ }^{4} 10$ of them with a second practitioner, six of whom were specialist anaesthetists. All their patients were young and healthy and the operations were brief and trivial. Thus even with specialists giving the anaesthetics there were more of these tragedies than with operator-anaesthetists, and this despite the fact that specialist administrations are outnumbered almost two to one by operator-anaesthetist administrations. ${ }^{5}$ It would seem that the much argued ${ }^{5}$ and widely publicized danger in the dentist giving his own anaesthetics has been exaggerated.

Nevertheless, I no longer support this practice. When doing so previously, I stipulated, 1 amongst other provisos, that there should be in attendance at least two chairside assistants of suitable status and training and that the patient should be treated lying down. These provisos have not always been met, and fearing that what I regard as inadequate care of the patient may 
be widespread I now accept the majority view that there should be a second person present to give the anaesthetic; but this would bring no gain in safety unless that person fully understood and kept constantly in mind the peculiar danger of anaesthesia in the dental chair. Whether this person needs to be qualified in medicine or dentistry is open to question. I think not and have suggested ${ }^{6} 7$ the establishment of an alternative grade.-I am, etc.,

Salisbury, Wilts

J. G. BOURNE

1 Bourne, J. G., British Medical fournal, 1967, 3, 616.

2 Bourne, J. G., Lancet, 1966, $1,879$.

3 Bourne, J. G., Anaesthesia, 1970, 25, 473.

Bourne, J. G., Lancet, 1973, 1, 35.

Ministry of Health, Dental Anaesthesia, Report of

a foint Subcommittee of the Standing Medical and Dental Advisory Committee. London,

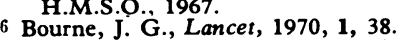

6 Bourne, J. G., Lancet, 1970, 1, 38.
7 Bourne, J. G., Lancet, 1970, 2, 1311.

\section{Depression and Organic Disorder}

SIR,-On my return from abroad I have read the correspondence from Dr. G. Dodds (22 September, p. 638) and from Dr. Irene P. Rowlands and my colleague Mr. A. N. Smith (27 October, p. 234).

Dr. Rowlands interprets me correctly when she writes that I "merely intended that one must not lose sight of depression as the 'writing on the wall' in carcinoma occurring in later life." It was indeed an off-the-cuff remark in closing the meeting as I noted that this feature had not arisen in the discussion at the clinicopathological conference. Nevertheless, Dr. Dodd's remarks on the many other reasons why such a patient might well develop depression are perfectly pertinent and Mr. Smith has answered appropriately the question that he raised relating to the absence of this factor in the retrospective survey. In the event, my closing remark has had the advantage of greater publicity than it would have achieved if I had surrounded it with provisos.

I am unsure what Dr. Rowlands meant by my "usual flair for diagnostic slogans," but as the tone of the letter is clearly friendly I shall take the liberty of assuming that flair compensates for slogans.-I am, etc.,

Gastro-Intestinal Unit, Western General Hospital, Edinburgh

\section{Effect of Beta-receptor Stimulation on the} Platelet Count

SIR,-The intravenous infusion of adrenaline causes an instant release of platelets from the exchangeable splenic platelet pool (E.S.P.P.), resulting in a simultaneous increase in the peripheral platelet count. ${ }^{1-4}$ The mechanism behind this effect of adrenaline on the E.S.P.P. is, however, unclear. In view of the fact that adrenaline stimulates the alpha- as well as the beta-receptors it was considered of interest to study the possible effect of more selective stimulants on the peripheral platelet count. Therefore five healthy male volunteers aged 24-39 (mean 30) years were studied during an intravenous infusion of isoprenaline lasting 20 minutes $(0.015 \mu \mathrm{g} / \mathrm{kg}$ body weight $/ \mathrm{min})$ on two occasions. Ten minutes before the second infusion the subjects received $10 \mathrm{mg}$ of propranolol intravenously at a constant rate over a 10-minute period. For determination of th: platelet count venous blood was collected at five-minute intervals throughout the $\mathrm{ex}_{2}$ )eriment. The last sample was drawn 20 minutes after the withdrawal of isoprenaline. The counting of platelets was carried out with a Coulter counter Model F, as described elsewhere, ${ }^{5}$ and the absence of platelet aggregates in the blood samples was confirmed by phase microscopy.

During the first experiment a progressive fall in the platelet concentration was observed in all subjects. After 15 minutes of isoprenaline infusion the mean platelet count had decreased to $82 \%$ of the baseline value. After the withdrawal of isoprenaline the platelet count referred to the baseline within 20 minutes. During the second study, when the subjects were pretreated with propranolol, there was no significant change in the peripheral platelet concentration in response to isoprenaline administration.

Thus while adrenaline causes an increase in the peripheral platelet count, there is a decrease in the peripheral platelet concentration in response to isoprenaline. This latter effect of isoprenaline can effectively be blocked if the subject is pretreated with propranolol, a beta-blocking agent. Since it is known that adrenaline exerts its effect on the peripheral platelet count by decreasing the E.S.P.P.1-4 it may well be that isoprenaline exerts an opposite effect on the spleen. These effects might well be mediated by alphaand beta-receptors.-We are, etc.,

JACK KUTTI

SOODABEH SAFAI-KUTTI ULF SMITH

Department of Medicine,

Sahlgren's Hospital

Goteborg, Sweden

Aster, R. H., Fournal of Clinical Investigation, $1966,45,645$.

otilainen, M., Scandinavian fournal of Haematology, 1969, suppl. 5

年, Studies on Platelet Kinetics in Polycythaemia Vera, p.

4 Branehög, I., Weinfeld, A., and Roos, B., British Fournal of Haematology, 1973, 25, 239.

Kutti, J., and Weinfeld, A., Scandinavian fournal of Haematology, 1971, 8, 336.

\section{Anaemia in the Elderly}

SIR,-Dr. J. H. Thomas (3 November, p. 288) reviewed the causes, types, and treatment of anaemia in the elderly and pointed out that a deficient vitamin $\mathrm{C}$ intake is associated with a normocytic and sometimes a macrocytic anaemia. Concomitant with the iron deficiency anaemia commonly found in the elderly, a deficiency of vitamin $C$ is often encountered. ${ }^{2}$ The metabolism of iron is closely related to that of vitamin $\mathrm{C}^{3}$ Iron absorption is enhanced in the presence of vitamin $C,{ }^{4}$ and its mobilization from transferrin to ferritin in the liver and vice versa is dependent on an adequate supply of ascorbic acid. ${ }^{6}$ Optimal haemopoiesis is possible only in the presence of iron and the maturation factors, vitamin $\mathbf{B}_{12}$, folic acid, pyridoxine, and also ascorbic acid, in the bone marrow. In the presence of an adequate supply of the maturation factors, but with a deficiency of vitamin $\mathrm{C}$, optimal haemopoiesis does not take place during adolescence ${ }^{2}$ or in the elderly. ${ }^{28}$ Adequate supplementa- tion in a ra:io of five parts of vitamin $\mathrm{C}$ to one of iron has been shown to enhance haemopoiesis in the elderly in the absence of deficiency of the other factors. ${ }^{389}$

Dr. Thomas suggested a daily intake of an adequa:e amount of protein, $10-12 \mathrm{mg}$ of iron, 2-4 $\mu \mathrm{g} B_{1: 2}, 100 \mu \mathrm{g}$ folic acid, $2 \mathrm{mg}$ pyridoxine, and $35 \mathrm{mg}$ vitamin $\mathrm{C}$, to ensure an adequate supply of these haemopoietic factors for the daily needs of elderly people. Though a daily intake of more than $10 \mathrm{mg}$ of vitamin $\mathrm{C}$ is adequate to prevent scurvy, ${ }^{10}$ $35 \mathrm{mg}$ is not an adequate daily intake to

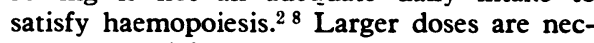
essary to satisfy other metabolic demands of a physiological $^{11}$ or of a pathophysiological nature. ${ }^{12-14}$-We are, etc.,

H. S. LoH C. W. M. WILSON

Department of Pharmacology,

University of Dublin,

Trinity College,

Taylor, G. F., British Medical fournal, 1973, 1.292.

, H. S., and Wilson, C. W. M., International fournal for Vitamin and Nutration Research,

Loh, H. S., and Wilson, C. W. M., Lancet, 1971, 2, 768

Conrad, M. E., and Schade, S. G., Gastroenterology, 1968, 55, 35 .

Mazur, A., Annals of the New York Academy of Sciences, 1961, 92, 223.

6 Cox, E. V., in Vitamins and Hormones, ed. R. S. Harris, I. G. Wool, and J. A. Loraine, vol. 26, Loh, H. S., and Wilson, C. W. M., International fournal for Vitamin and Nutrition Research, $1971,41.445$.

8 Wilson, C. M. W., and Loh., H. S., Nutrition Reports International, 1971, 4, 371

Lee, P. C., Ledwich, J. R., and Smith, D. C., Canadian Medical Association fournal, 1967, Goudsmith, G. A., Annals of the New York Academy of Sciences, 1961,92, 230.

Wilson, C. W. M., and Loh, H. S., Lancet, 1973, 2. 859 .

2 Wilson, C. W. M., and Loh, H. S., Lancet, 1973, 3 Wilson, W. M., Loh. H. S., and Foster, F. G., fournal of Clinical Pharmacology, 4 Wilson, C. W. M., Loh, H. S., and Foster, F. G., European fournal of Clinical Pharmacology,
1973, 6, 196.

\section{E.S.R. versus Plasma Viscosity Readings} in the Old

SIR,-Following Dr. F. I. Caird's comprehensive account of laboratory findings in the old (10 November, p. 348) I would like to draw attention to some work relating raised erythrocyte sedimentation rate (E.S.R.) with normal or low plasma viscosity to either abnormally low packed cell volume or reduced plasma albumin level. ${ }^{1}$ Albumin disperses rouleaux formation and therefore tends to reduce the E.S.R. whereas globulin enhances rouleaux formation, tending to accelerate the E.S.R. Harris ${ }^{1}$ found that in some old people plasma albumin levels may be reduced in association with malnutrition or malabsorption in the absence of ana ${ }^{\circ}$ mia.

In our hospital group we have used plasma viscosity estimations in place of E.S.R.s for over eight years, the effects due to low packed cell volume or to changes in the red cell surface thus being eliminated. ${ }^{2}$ Low plasma viscosity readings suggest hypoproteinaemia, normal readings virtually exclude inflammatory response from whatever cause, and readings raised above normal require investigation. The test has the advantage of being cheap (virtually the cost of the apparatus), it is rapid (20 seconds per test) reproducible (coefficient of variation $<1 \%$ ), and suitable for postal samples (unlike the 